\title{
"ELES FAZEM DE TUDO PARA PEGAR AS \\ PESSOAS": ADMINISTRANDO NARRATIVAS DOS SOLICITANTES DE REFÚGIO NO BRASIL
}

RESUMO: Atribuir a qualidade (jurídica, política e humanitária) de refugiado a um sujeito pode ser compreendido como um procedimento banal ou meramente burocrático. Contudo, a definição legal está associada a disputas pelo sentido de ser refugiado que atravessam qualquer paradigma simplista de adequação. A seleção dos refugiados produz técnicas de gestão da heterogeneidade dos êxodos e ajuda a compreender o funcionamento do Estado e a governamentalidade das práticas dos agentes do universo institucional brasileiro de refúgio. Este artigo busca descrever e analisar os processos de construção da condição de refugiado a partir da dinâmica de elegibilidade do regime brasileiro. $O$ estudo foi realizado a partir de uma inspiração etnográfica e se propõe a problematizar o refúgio no Brasil pelo campo da Sociologia do Direito. Em um primeiro momento, será apresentado o mapa lógico que orienta os processos de elegibilidade e, em seguida, serão problematizados alguns dispositivos construídos $\mathrm{e}$ utilizados para avaliar a credibilidade da narrativa dos solicitantes de refúgio.

Palavras-chave: Refúgio no Brasil. Processo de elegibilidade. Análise de credibilidade. Governo de populações.
ABSTRACT: Assign the quality (legal, political and humanitarian) of refugee to a subject can be understood as a trivial or merely bureaucratic procedure. However, the legal definition is associated with disputes over the meaning to be a refugee, crossing any simplistic paradigm of adequacy. The selection of refugees produces management techniques of the heterogeneity of exoduses and helps to understand the functioning of the state and governmentality practices of the Brazilian institutional refuge universe agents. This article aims to describe and analyze the processes of construction of refugee status from eligibility dynamics of the Brazilian regime. The study was conducted from an ethnographic inspiration and intends to problematize refuge in Brazil by the field of Sociology of Law. At first, the logical map that guides the eligibility process will be presented and then will be discussed some devices constructed and used to assess the credibility of the narrative of asylum seekers.

Keywords: Refuge in Brazil. Process of eligibility. Credibility analysis. Government of populations.

\footnotetext{
${ }^{1}$ Doutoranda em Direito. Programa de Pós-Graduação em Direito - UFRJ.

${ }^{2}$ Doutor em Antropologia. Professor do Departamento de Teoria do Direito da Faculdade Nacional de Direito - UFRJ.
} 


\section{INTRODUÇÃO}

Quando se fala em "crise dos refugiados" no mundo, os números são assustadores. Falar de milhões de pessoas que tiveram que fugir de suas casas, centenas de milhares em condições precárias e insalubres de campos de refugiados, ou em milhares de migrantes e refugiados que morreram tentando fugir assusta porque traz a dimensão de toda uma coletividade que sofre. Sofre, porém, resiste. E a resistência é construída, nestes casos, pelo êxodo. Ao mesmo tempo, os números assustam porque se referem ao registro administrativo de pessoas, de vidas, de histórias de vida.

Por mais que os números possam indicar um movimento de massa, há outros movimentos que ressaltam o significado individual dessas fugas. Seja por motivações humanitárias para sobressaltar a morte de uma criança na praia, o sofrimento de um sobrevivente, o reencontro de uma família. Seja por questões da ordem de segurança nacional quando os Estados evocam medo de haver terroristas infiltrados no grupo. Seja por uma razão de governo que se preocupa em classificar cada história de vida a fim de enquadrá-la numa categoria de migrante ou refugiado.

A constituição do regime ocidental de administração dos refugiados no formato como conhecemos hoje se baseou numa definição de refugiado individualizada (HADDAD, 2008). ${ }^{3}$ Não é diferente no Brasil. De acordo com o artigo 1o da Lei 9.474 de 1997:

Será reconhecido como refugiado todo indivíduo que:

I - devido a fundados temores de perseguição por motivos de raça, religião, nacionalidade, grupo social ou opiniões políticas encontre-se fora de seu país de nacionalidade e não possa ou não queira acolher-se à proteção de tal país;

II - não tendo nacionalidade e estando fora do país onde antes teve sua residência habitual, não possa ou não queira regressar a ele, em função das circunstâncias descritas no inciso anterior;

III - devido a grave e generalizada violação de direitos humanos, é obrigado a deixar seu país de nacionalidade para buscar refúgio em outro país.

\footnotetext{
${ }^{3}$ O ACNUR (s.d., p. 39) identifica algumas maneiras dos Estados tratarem da identificação individual dos refugiados: através de procedimentos formais específicos, como é no caso brasileiro; no âmbito de procedimentos gerais para admissão de estrangeiros; por meios informalmente; de modo ad hoc para determinados fins relacionados a demandas dos refugiados.
} 
Isto é, a atribuição do status de refugiado a um migrante passa por uma análise individualizada acerca dos motivos que deram causa à saída de seu país de origem. Além da definição, a Lei 9.474/97 estabelece procedimentos para o reconhecimento da condição de refugiado, instituindo o que é denominado formalmente no universo do refúgio como elegibilidade. Basicamente, é realizada uma análise dos casos concretos de pedido de refúgio a fim de classificar se há adequação ou não ao conceito de refugiado adotado pelo governo brasileiro. Esse regime de elegibilidade cria, então, a figura do solicitante, de modo a diferenciar os sujeitos que são reconhecidos pelo Estado na condição de refugiados daqueles cujo status ainda não foi avaliado.

O formato de elegibilidade é fortalecido pelas políticas de governos ocidentais de economia desenvolvida, em que há um esforço por construção de critérios objetivos e rígidos a fim de analisar individualmente os casos. Elementos como credibilidade e análise de alternativa de fuga interna não são inerentes aos procedimentos de elegibilidade, mas foram elaborados como forma de apurar os mecanismos de seleção e gestão sob os auspícios do argumento de objetividade. O regime de elegibilidade está inserido numa ambivalência do instituto do refúgio, que implica permanente embate entre defesa de direitos humanos e de interesse político. Ou seja, se, por um lado, o refúgio se presta a uma finalidade humanitária; por outro lado, o instituto também se ampara num viés político, tendo em vista que o Estado, sob o respaldo da soberania, constrói contingentemente sua noção do que seja "refugiado".

No Brasil, a análise de elegibilidade é feita pelo Comitê Nacional para Refugiados (CONARE), também criado pela Lei 9.474/97. A partir desse formato de proteção e regulamentação, a relação entre instituições governamentais, da sociedade civil e de organismos internacionais é consolidada pelo desenho tripartite do CONARE, descrito como órgão de deliberação coletiva no âmbito do Ministério da Justiça pelo artigo 11 da Lei. Essas duas características do CONARE, órgão triparte e de deliberação coletiva, são as sementes do enorme campo de disputas em torno dos processos de elegibilidade. De modo geral, o sistema brasileiro de proteção aos refugiados e, por conseguinte, de elegibilidade ao refúgio opera com disputas incessantes de papeis, sentidos, práticas, direitos e estratégias. 
Nesse sentido, este artigo busca descrever e analisar os processos de construção da condição de refugiado a partir da dinâmica de elegibilidade do regime brasileiro. 0 estudo foi realizado a partir de uma inspiração etnográfica e se propõe a problematizar o refúgio no Brasil pelo campo da Antropologia Jurídica. Em um primeiro momento, será apresentado o mapa lógico que orienta os processos de elegibilidade e, em seguida, serão problematizados alguns dispositivos construídos e utilizados para avaliar a credibilidade da narrativa dos solicitantes de refúgio.

\section{A SELEÇÃO DO INDIVÍDUO REFUGIADO}

Para Alexander Betts, Gil Loescher e James Milner (2012), os Estados ocidentais tornaram a elegibilidade do status de refugiado dependente de aspectos individuais, não de pertencimento a circunstâncias de um grupo. É uma forma de condução das histórias de vida para produção de identidades, de uma identidade sobre ser refugiado. A prática de individualização da condição de refúgio é construída por dispositivos ${ }^{4}$ estatais de fixação de identidade e de controle sobre os indivíduos.

Dentre algumas medidas administrativas cujo respaldo é a promoção da cidadania, Cédula de identidade (RG - Registro Geral), Carteira de Trabalho e Previdência Social (CTPS), passaporte, etc., nos impõe uma identidade ao certificar determinados dados como verdadeiros sobre o indivíduo. O que está registrado sob o auspício do Estado é verdadeiro; o que é contrário ao registro é falso. Os documentos que certificam a condição de um indivíduo têm efeito de reconhecimento, mas também de controle (HERZFELD, 1992).

A categoria de indivíduo, aliás, é produto de dispositivos políticos que caracterizam a modernidade. Este controle sobre cada indivíduo, nos impõe uma individualidade, uma identidade. Na cultura ocidental capitalista, nós somos individualizados, queiramos ou não. "Nossa individualidade, a identidade obrigatória de cada um é o efeito do poder e um

\footnotetext{
${ }^{4}$ Foucault (1979, p. 244) define dispositivo como "um conjunto decididamente heterogêneo que engloba discursos, instituições, organizações arquitetônicas, decisões regulamentares, leis, medidas administrativas, enunciados científicos, proposições filosóficas, morais, filantrópicas. Em suma, o dito e o não dito são os elementos do dispositivo. O dispositivo é a rede que se pode estabelecer entre estes elementos".
} 
instrumento contra o qual se mais teme: a força e a violência dos grupos" ${ }^{5}$ (FOUCAULT, 1974 apud REVEL, 2008, p. 77). Num movimento de reação, a produção do sujeito enquanto indivíduo neutraliza as formas de resistência das coletividades.

Conforme práticas que observamos, é justamente por temer a entrada de grandes grupos de migrantes que o governo brasileiro tem justificado a necessidade de avaliar individualmente cada pedido de refúgio. Com a adoção do novo modelo de parecer, ${ }^{6} \mathrm{em}$ 2015, e do Termo de Solicitação, em 2016, ${ }^{7}$ o governo brasileiro deu ênfase à análise de credibilidade $^{8}$, como é denominado tecnicamente. O processo de elegibilidade - conjunto de procedimentos para que um solicitante de refúgio seja reconhecido institucionalmente por um Estado na categoria jurídica de refugiado - infere que apenas será concedida documentação formal para permanência no Brasil pelo instituto do refúgio àquele indivíduo que for realmente refugiado. Ser refugiado não é uma categoria de autoidentificação. Não basta os indivíduos declararem ter fundadas razões para não quererem ou não poderem voltar para seu país de naturalidade. A condição de refúgio é construída pelo próprio Estado e validada por ele. Isto quer dizer que o CONARE seleciona individualmente as histórias de vida narradas, classificando-as de acordo com indícios de verdade.

Neste sentido, para ser reconhecido como refugiado num processo de elegibilidade, o solicitante deve ter uma narrativa verossímil e condizente com a pesquisa sobre país de origem (COI, na sigla em inglês para Country of Origin Information) realizada pelo órgão decisório. De acordo com o Alto Comissariado das Nações Unidas para Refugiados (ACNUR), o processo de determinação da condição de refugiado considera dois âmbitos de análise: um interno, em que se avalia a consistência da narrativa do solicitante; e um

\footnotetext{
${ }^{5}$ Tradução livre do trecho original em francês "notre individualité, l'identité obligatoire de chacun est l'effect du pouvoir et un instrument contre ce qu'il craint le plus: la force et la violence des groupes".

${ }^{6} \mathrm{O}$ novo modelo de parecer adotado pelo governo brasileiro foi apresentado na seção sobre descrição formal do processo.

${ }^{7}$ O Termo de Solicitação aqui referido é aquele aprovado pela Resolução no 22 do CONARE, em 2015. O mesmo será discutido mais adiante.

${ }^{8}$ A expressão "análise de credibilidade" é a categoria nativa utilizada, mas outros termos equivalem a seu significado, como avaliação de credibilidade.
} 
externo, em que compara a informação fornecida no relato com os dados encontrados sobre o contexto do país de origem.

Não há regulamentação específica para os procedimentos de reconhecimento de status. Ocorre que o ACNUR participa ativamente da administração dos procedimentos de análise de credibilidade. No Brasil, além de participar das discussões e das disputas na instância do CONARE, fornece assessoria ao governo e realiza treinamento para os agentes governamentais, da sociedade civil e do próprio ACNUR que trabalham com o processo de elegibilidade. Há também manuais do ACNUR sobre "procedimentos e critérios para determinação da condição de refugiado" e "metodologia e técnicas para entrevistar solicitantes de refúgio". Assim, este organismo de atuação internacional informa os Estados, criando um intercâmbio de influência sobre os parâmetros de análise utilizados.

Uma das principais justificativas para análise de credibilidade apresentada formalmente pelo ACNUR é a de que a definição clássica, que se baseia na constatação de "fundado temor de perseguição", realça mais o elemento subjetivo da definição - "temor" - em detrimento da situação objetiva do país de origem do solicitante de refúgio. Dessa forma, a avaliação das declarações narradas pelo solicitante é mais determinante para o processo de elegibilidade do que o exame da conjuntura do local de procedência. Nos casos em que os fatos apresentados não são de identificação imediata, o entendimento institucional é que a avaliação de credibilidade deve considerar os antecedentes pessoais e familiares do solicitante. Isto é, a conduta do solicitante e seu histórico de vida que puderem ser verificados ou acreditados influenciarão o mapeamento da confiabilidade das suas narrativas.

O posicionamento do ACNUR é que a análise da história do solicitante e da sua credibilidade sobre os elementos apresentados no pedido de refúgio é componente central para tomada de decisão sobre a condição de refugiado num processo de elegibilidade. O sentido da análise se relaciona com uma busca pela verdade sobre os motivos que fundamentam o pedido: "avaliar a credibilidade do solicitante é determinar a veracidade de sua declaração", diz o manual de 'Metodologia e Técnicas para Entrevistar Solicitantes de Refúgio' do ACNUR (2013, p. 53). 
Diferente do governo e do ACNUR, a sociedade civil desempenha uma função incerta em termos da análise de credibilidade. Uma advogada da Cáritas Arquidiocesana do Rio de Janeiro $(C A R J)^{9}$ afirmou veementemente que "a gente não faz análise de credibilidade". Em observação direta, notamos que os advogados da sociedade civil se afirmam de uma forma crítica em relação ao foco do processo de elegibilidade ser a análise de credibilidade. Parte do trabalho do conjunto de atividades que compõem o setor de proteção legal é explicar aos refugiados as nuances e as armadilhas do processo, num esforço de evitar que pedidos sejam indeferidos por inabilidade em lidar com as dinâmicas do processo. Assim, ainda que os advogados não se proponham a fazer avaliação de credibilidade, eles acabam lidando com este tema todo o tempo, nas entrevistas, nas orientações aos refugiados, na elaboração dos pareceres, na participação do GEP e da Plenária.

O modo de gestão do processo é capilarizado nas relações entre os atores e nos procedimentos voltados para os refugiados. Em conversa com um refugiado sobre o processo de solicitação de refúgio no Brasil, ele disse: "eles fazem de tudo para pegar as pessoas". Alguns exemplos citados foram as perguntas extremamente detalhadas sobre a cidade onde vivia, a comparação entre as narrativas de um solicitante no processo e entre solicitantes da mesma nacionalidade, e perguntas para mulheres sobre função do marido no partido. Ele falava sobre estratégias que os refugiados vão aprendendo uns com os outros para poderem serem melhor sucedidos nas entrevistas, indicando haver uma produção coletiva de habilidade. Para ele, a forma como o processo é conduzido é reflexo de uma política xenofóbica do governo.

Todo o processo de elegibilidade é pensado a partir do pressuposto de análise individual dos pedidos de refúgio. Isto porque, do ponto de vista da administração do Estado, é preciso diferenciar refugiados das demais categorias de migrantes, privilegiando a flexibilidade de controle migratório para aqueles que genuinamente possuem "fundado temor de perseguição". Ocorre que, para este fim de categorização, a prática de

\footnotetext{
${ }^{9}$ A Cáritas Arquidiocesana do Rio de Janeiro há quarenta anos trabalha com atendimento a refugiados e solicitantes de refúgio e é representante titular da sociedade civil no CONARE desde sua criação, em 1997.
} 
reconhecer individualmente a condição de refúgio implica, ao menos, dois efeitos totalizantes sobre esses sujeitos.

Em primeiro lugar, ao exigir um exame individualizado, a administração do processo provoca um deslocamento da representação do refugiado em relação à conjuntura sociocultural em que vivia. É como se as histórias de vida pudessem - e, em termos de elegibilidade, devessem - ser separadas de um contexto de vida, de violência, de luta, de fuga. Os efeitos da guerra sobre as pessoas variam em grau. A questão mais fidedigna à complexidade dos conflitos não é se ou não uma pessoa é a atingida pela guerra, mas como, por quais mecanismos de violência - morte, estupro, bala perdida, mina terrestre, sequestro, negligência de doenças, escassez de alimento -. A não ser que o temor seja entendido como fobia numa dimensão psicológica, o medo é construído coletivamente. Dificilmente alguém de um país em conflito, como República Democrática do Congo (RDC), Nigéria, Colômbia, está isento de um temor de sofrer violência, a despeito de ter sido individualmente ameaçado ou não.

O percurso classificatório é uma forma de poder sobre a verdade que quer relacionar os acontecimentos - a informação do país de origem - aos refugiados ao invés de compreender os refugiados a partir dos acontecimentos. Esta leitura se remete aos fundamentos do instituto do refúgio conforme ele foi criado no contexto europeu de pós-II Guerra Mundial e início de Guerra Fria. Em geral, a força administrativa sobre as populações neste regime tende a atribuir as conquistas e os erros à responsabilidade individual ao invés de serem compreendidos de um ponto de vista social. Os procedimentos de elegibilidade implicam uma supervalorização do indivíduo em detrimento das redes nas quais ele está inserido.

A noção individualizada do refúgio se coaduna com uma governamentalidade que pensa a migração com foco nos eventuais riscos provocados pela chegada dos migrantes e refugiados. A perspectiva é sobre os efeitos da imigração e não da emigração. Os critérios são formados a partir das ameaças e das afrontas que o migrante pode causar ao Estado. Em decorrência disso, é uma razão que não privilegia as razões para o êxodo, mitigando o direito de fuga dos migrantes. O direito de fuga dos refugiados é justificado na medida em que a saída é considerada o fator determinante, e não a chegada. 
São muitos os casos que poderiam ilustrar como essa problemática da credibilidade aparece nas discussões sobre deferimento e indeferimento dos pedidos. A cargo de exemplo, podemos resgatar o caso de um solicitante paquistanês que estava em pauta com recomendação de indeferimento pelo CONARE em 2015. Sendo o solicitante proveniente do Paquistão, houve questionamento por parte de alguns agentes do universo brasileiro de refúgio $^{10}$ acerca do motivo do Termo de Solicitação ter sido preenchido em espanhol, sugerindo dúvidas da veracidade da sua narrativa. No mesmo sentido, um agente afirmou que o solicitante estava mentindo porque ele não havia informado no formulário que falava espanhol, enquanto outro ponderou que o solicitante explicou na entrevista que morou no Equador e por isso entendia um pouco da língua espanhola, ao passo que outros questionaram a nacionalidade do solicitante. Toda uma discussão se desenvolveu sobre a possibilidade de confiar ou não no solicitante. A coordenação do CONARE afirmou que os critérios do Comitê não são por nacionalidade, mas pelos indivíduos.

No universo brasileiro de elegibilidade, a administração das narrativas é do ponto de vista do migrante que fala sobre sua motivação para fuga, não da situação do local de origem ou de uma coletividade, como nos apresenta Ângela Facundo Navia (2014). Nesse caso, como na grande maioria das discussões que acompanhamos sobre a elegibilidade, a avaliação negativa sobre a credibilidade do fato narrado pelo solicitante aparece como motivo para indeferimento dos pedidos. Assim, a produção das histórias de vida ao longo do processo passa por mecanismos de descolamento do indivíduo em relação à sociedade.

Em casos de países com notória crise humanitária, violência generalizada, ou em situação de grave violações de direitos humanos, as disputas acerca da determinação de status de refugiado dificilmente passam por dúvidas sobre a existência ou não de tal violência. Nos pareceres de elegibilidade e nas discussões sobre os casos no CONARE, a prática não é de questionar, por exemplo, a violência perpetrada pelos paramilitares na Colômbia, as atrocidades cometidas pelo Boko Haram ${ }^{11}$ na Nigéria, a brutalidade do

\footnotetext{
${ }^{10}$ A chave de análise sobre atores e instituições que lidam com refúgio no Brasil é categorizada por Ângela Facundo Navia (2014) como "universo institucional brasileiro de refúgio", que nos serviu de base para desenvolvimento desse texto.

${ }^{11}$ De acordo com a Anistia Internacional (2016), o grupo armado Boko Haram, em conflito com o exército nigeriano, causou a morte de milhares de civis e os deslocamentos de mais de dois milhões de pessoas até o fim do ano de 2015.
} 
conflito no Afeganistão ou o abuso sexual generalizado contra as mulheres na República Democrática do Congo. Paralelamente ao esforço de confirmar a nacionalidade alegada pelo solicitante, as disputas são sobre se uma pessoa é "realmente" afetada pelo entorno em questão ou não. É gerido um entendimento de que a situação de um país é distinguível da vulnerabilidade de uma pessoa neste país.

Valorizar histórias de vida não é sinônimo de torná-las uma questão individualizada. Este regime político e administrativo que faz a elegibilidade depender de uma análise individualizada ofusca as circunstâncias e responsabiliza, inclusive moralmente, o indivíduo. As histórias de vida são construídas invariavelmente em redes de relações econômicas, sociais, culturais, políticas. Contudo, é justamente a individualização totalizante que torna possível a administração das populações e o controle dos corpos. As representações suscitadas por este regime de análise de credibilidade apresentam uma dimensão biopolítica sobre a administração das narrativas e, por conseguinte, das histórias de vida e da própria vida. A biopolítica é uma forma, desde o século XVIII, de racionalizar "os problemas postos à prática governamental pelos fenômenos próprios de um conjunto de viventes constituídos em população" (FOUCAULT, 2008, 431).

Seguindo o pensamento de Foucault, a produção do indivíduo refugiado (individualização nos processos de refúgio), corresponde a uma gestão massificada desta população. E, como tal, é um dispositivo de poder que se exerce sobre os corpos, as multiplicidades, os movimentos, os desejos e as forças. O modus operandi do Estado imputa uma moralidade aos indivíduos para orientar como seus corpos vão agir.

Além disso, o regime de análise de credibilidade pressupõe uma noção de refugiado como um todo homogêneo. O ponto de vista de indivíduo implica um modo de lidar com histórias de vida como se os sujeitos fossem indivisíveis, indivisos, permanentemente coerentes e fixos. Devido ao quesito de coerência e consistência, o processo de elegibilidade, tal como ele é, produz uma negação da multiplicidade de experiências, relações, medos e desejos que podem se acumular numa pessoa.

A aposta na análise de credibilidade se apoia na possibilidade de detectar verdades e falsidades na reconstrução narrativa do solicitante, o que provoca também um exame sobre o aspecto moral a seu respeito. A menos que a inverdade seja uma estratégia de 
resistência anteriormente aceita por lei, como a não criminalização do uso de documentos falsos para entrada no país na condição de solicitante de refúgio, a mentira é tida como uma expressão negativa da moralidade do refugiado. Uma vez que as narrativas sobre os refugiados são moralizadas e os colocam na condição de vítimas, os solicitantes de refúgio devem se apresentar fora das zonas de dúvida e confusão para serem aceitos. Para se adequarem a este regime, os refugiados "têm que se desfazer dessas ambiguidades, contradições, dúvidas e esquecimentos que costumam caracterizar as experiências vitais das pessoas" (VIANNA; FACUNDO, 2015).

Conforme os critérios anteriormente apresentados, em normativas e na prática, para definição da condição de refúgio, a administração de indivíduos traz hierarquizações políticas e morais entre os refugiados e os eventuais outros grupos de migrantes. Segundo o regime de elegibilidade estabelecido e na forma como é instruído, o indivíduo refugiado é aquele que não é migrante econômico, não precisa mentir, pois a verdade da sua narrativa torna-se evidente depois de meticulosos testes de credibilidade. $\mathrm{O}$ indivíduo refugiado é apenas refugiado, cem por cento refugiado.

Portanto, a análise de credibilidade é feita sobre os solicitantes de refúgio, buscando estabelecer critérios de verdade sobre as narrativas individuais apresentadas. A gestão desta análise se ampara em representações de noções como verossimilhança, confiança, coerência, consistência, razoabilidade, veracidade, aceitabilidade, genuinidade, evidência, sinceridade. Os agentes de Estado que lidam com os pedidos de refúgio, em especial aqueles que entrevistam, redigem os pareceres e os que participam das disputas no âmbito decisório do CONARE, trabalham numa disputa que visa selecionar os refugiados legítimos através dos processos de elegibilidade. Dessa maneira, as práticas divisoras que diferenciam quem é de quem não é refugiado constituem a condição do refúgio por meio de uma identidade imputada ao indivíduo como se fosse própria.

\section{3 “NÃO HESITE EM REPETIR PERGUNTAS"}

O papel do ACNUR na gestão do modelo de análise de credibilidade diz respeito a sua posição central no universo geral do refúgio, que lhe dá uma posição de poder decorrente de seu lugar de expertise sobre o tema. Como consequência, o seu modo de 
ação baseado em critérios de conhecimento de causa gera autoridade aos seus discursos e legitima sua produção de saberes sobre a administração de refugiados. Nesse sentido, o ACNUR elenca algumas regras básicas para os agentes incumbidos na tarefa de identificar a veracidade ou não das alegações do refugiado:

Estratégia básica - Faça a avaliação da credibilidade somente depois de ter obtido toda a informação (por exemplo, depois de esclarecer a história). Tente definir os aspectos fundamentais para avaliar a credibilidade da solicitação. Defina e ajuste o grau de precisão e detalhe que pode ser exigido do solicitante. Utilize perguntas claras e diretas. Não faça juízos de valor precipitados e não hesite em repetir perguntas ou aprofundar fatos relevantes para a solicitação. Lembre-se de conectar uma pergunta à outra (ACNUR, 2013, p. 54).

Observando o tom das orientações, sobressaem alguns elementos determinantes da prática de determinação de status. Sugestões de como ajustar o "grau de precisão" são de uma esfera mais abstrata. Por isso, encontrar a precisão de um relato é, muitas vezes, um caminho de busca sem limite por eventual evidência da genuinidade do refugiado. $O$ que "pode ser exigido do solicitante"? Eis é um quesito contingente que explora a capacidade de coerência de um indivíduo. Não há delimitação clara sobre o alcance da exigência de minúcia de informação que pode ser cobrada. É um horizonte a ser definido na prática de inquirição e de decisão.

Assim, a avaliação de elegibilidade de um solicitante se exerce através de táticas que exploram o limite do que pode ser exigido do sujeito qualitativa e quantitativamente. Em conversa informal, alguns refugiados comentaram que suas entrevistas de elegibilidade foram longas e outros contaram que perguntas foram direcionadas a todos os membros da família presentes, inclusive às crianças. Esta técnica indica como os detalhes do modo de operação do processo de elegibilidade são dispositivos de poder, decorrentes de uma lógica de elegibilidade, em relação ao sujeito que depende do reconhecimento estatal de sua condição de refugiado.

Outro exemplo do exercício desses dispositivos diz respeito à estratégia de fazer a mesma pergunta repetidas vezes é adotada no sistema brasileiro ao longo do processo. De modo geral, os solicitantes de refúgio que efetivam pedido no Rio de Janeiro, enfrentam as perguntas centrais - referentes ao motivo de saída do país de origem, por exemplo - ao menos quatro vezes: no Termo de Solicitação, no Termo de Declaração, na entrevista com 
a sociedade civil, e na entrevista de elegibilidade oficial. Nesta última, há casos em que o entrevistador repete a mesma pergunta, de forma idêntica ou com outras palavras. Independentemente da honestidade da fala do solicitante, o encargo de responder o mesmo questionamento por diversas vezes tende a aumentar as chances de contradição. Ou seja, além da contradição poder ser uma expressão do solicitante em si, ela também é uma produção que se opera na relação do solicitante com o processo devido à lógica governamental de busca por precisão, como podemos ver na repetição de perguntas. As informações obtidas são fatos produzidos numa relação, não são evidências encontradas por uma das partes. Ambos os solicitantes e os atores governamentais e não governamentais participantes do processo são sujeitos ativos numa relação construtiva da condição de refugiado.

Outra regra indicada pelo ACNUR para as pessoas incumbidas da avaliação de credibilidade é:

\begin{abstract}
Você também deve considerar a fluidez do testemunho (ou seja, a incidência de hesitação) assim como a sua clareza e rigor. Se forem apresentadas duas declarações, escrita e oral, deve haver uma coerência global entre as duas. Isto significa não apenas que a sequência de eventos e as declarações de suporte devem ser lógicas e consistentes, mas também que deve haver algum tipo de ligação entre lugares, horários, eventos e outros fatores que formam a base da solicitação (ACNUR, 2013 p. 55).
\end{abstract}

A ponderação da "fluidez do testemunho" é um fator de impacto na formação da confiabilidade da fala de um refugiado. Aspectos de expressão corporal e postura influenciam na construção subjetiva do perfil do solicitante, muito embora possam parecer irrisórios no contexto de uma fuga. A administração da mentira - ou de omissão da verdade - é construída por imputações morais, com efeitos políticos, sobre os solicitantes de refúgio (GRIFFITHS, 2012).

Aliás, a hesitação tem uma conotação cultural. O que é considerado uma hesitação para a cultura ocidental não necessariamente o é para outras variações culturais. Certo é que, na cultura ocidental, quando uma pessoa mente, ela tende a hesitar ou não transmitir tanta certeza no que fala. De todo modo, uma mentira pode ser contada de uma maneira muito convincente e hesitar não é sinônimo de inverdade. Portanto, este método implica o risco de produzir um julgamento negativo sobre a hesitação, que pode ter motivações 
variadas, como nervosismo, ansiedade, característica elocutiva. Muitos refugiados vêm de comunidades em que não estão acostumados a lidar com entrevistas ou a falar com agentes do governo.

Estas orientações tendem a fazer com que os comportamentos fora do padrão do que a razão governamental considera crível sejam interpretados com uma carga de negatividade. A análise de credibilidade não deixa de ser uma lente com a qual entrevistadores e tomadores de decisão enxergam expressões e narrativas. Por isso, uma eventual falta de sensibilidade à diferença cultural pode resultar efeitos de interpretação em desfavor do solicitante.

A "sequência de eventos" também sobressai nesta recomendação do ACNUR. Na prática decisória do CONARE em 2015, já com a adoção do modelo de parecer que tem análise de credibilidade registrada na fundamentação, a cronologia dos fatos foi fator recorrente para formar a aceitabilidade dos casos. A carência de clareza na ordem dos eventos é prejudicial ao solicitante. Em alguns casos que acompanhei no GEP, a reconstituição dos fatos realizada pela sociedade civil e pelo governo não são compatíveis, gerando disputa na instância deliberativa do CONARE.

Ainda sobre a razoabilidade do que se pode exigir do solicitante, chama atenção a importância atribuída pelo ACNUR (no trecho supramencionado) a elementos como horário para formar a apreciação do pedido de refúgio. O trajeto de uma fuga pode demorar meses e geralmente é atravessado por riscos e tensões. Estabelecer horários e colocá-los em relação a eventos pode não ser uma tarefa fácil. Além disso, nem todas as culturas se orientam por horários fixados como na sociedade ocidental. Pode haver ruídos de comunicação entre o que o governo quer verificar e entre a forma de estar no mundo do solicitante.

São dispositivos minuciosos como estes que constroem a razão governamental acerca do processo de elegibilidade. São, aliás, os dispositivos de poder sobre os sujeitos que fundamentam o governo humanitário, como descreve Didier Fassin (2010). As relações de poder produzidas a cada pergunta, a cada interpretação, informam o perfil da administração da noção de refugiado numa perspectiva de desconfiança e de probabilidades. Os refugiados, geridos na categoria de solicitantes de refúgio devido ao 
processo de elegibilidade, se movem na condição de corpos não confiáveis, tendo em si a ambiguidade de serem ao mesmo tempo colocados na categoria de vítimas e considerados como potencialmente perigosos (VIANNA: FACUNDO, 2015).

A construção da condição de refugiado é construída em todo o percurso do processo de elegibilidade, passando pelas fases de preenchimento do Termo de Solicitação, entrevistas, discussão técnica e a decisão colegiada em si. Mesmo a entrevista, que a princípio serviria de subsídio para posterior análise, produz um julgamento sobre a narrativa do solicitante. O próprio $\operatorname{ACNUR}(2013$, p. 50) recomenda que as tarefas pertinentes à entrevista devem incluir avaliação de credibilidade.

Nas suas orientações sobre metodologia para entrevistar solicitantes de refúgio constam algumas técnicas de interesse para o tema de análise de credibilidade:

As tarefas para garantir a validade das declarações incluem:

- Manter um bom relacionamento com o solicitante;

- Detectar fatores inibitórios que tornam o solicitante relutante ou incapaz de fornecer informações válidas.

As tarefas para garantir a confiabilidade incluem:

- Identificar e resolver contradições, discrepâncias ou omissões na história do solicitante;

- Identificar e resolver contradições percebidas entre as informações pessoais fornecidas pelo solicitante e a informação geral que está disponível sobre a situação de seu país de origem (ACNUR, 2013, p. 50).

Estas tarefas são apontamentos norteadores para a prática dos entrevistadores nos processos de elegibilidade. Elas entram no rol de técnicas utilizadas pelo aparelho estatal para manejar fatos e evidências produzidas no processo que fundamentam o reconhecimento ou o não reconhecimento de uma pessoa como refugiada. Nestes aspectos de administração, o governo instrumentaliza critérios de pertencimento, criando mecanismos de controle de populações, seus movimentos e seus pleitos (BUTLER; SPIVAK, 2010). Com base nas técnicas desenvolvidas para analisar a veracidade das narrativas dos solicitantes, vemos que a governamentalidade opera nos pormenores da vida e dos direitos.

Devido ao aumento abrupto e exponencial das solicitações e à diversidade de nacionalidade (mais de 80), o governo brasileiro identificou uma inabilidade em lidar com a administração de tal demanda. Por isso, juntamente com o ACNUR, investiu num conjunto de ações com vistas a consolidar uma Iniciativa de Fortalecimento do Procedimento de 
Determinação da Condição de Refugiado no Brasil (IFPDCR). Nesse contexto, esses dois atores contrataram, em 2014, uma consultoria para fazer avaliação da qualidade e da eficiência dos procedimentos nacionais de "Determinação da Condição de Refugiado". ${ }^{12}$

O consultor havia atuado no sistema canadense de avaliação dos pedidos de refúgio - o Immigration and Refugee Board ${ }^{13}$ - em que os procedimentos ocorrem judicialmente. A principal motivação apresentada para os agentes de Estado e atores da sociedade civil sobre sua consultoria era devido sua experiência em lidar com aumento inesperado de refugiados e um passivo significativo de casos para serem julgados. Além disso, ele integrou a Associação para Juízes de Direito de Refúgio (IARLJ, na sigla em inglês para Association of Refugee Law Judges). Esta organização, que tem proximidade com o ACNUR, trabalha para promoção de parâmetros legais para determinação de status de refugiado ao redor do mundo.

Como mencionado, a participação do ACNUR nestes mecanismos para padronização dos processos torna-o um organismo fundamental para gestão do regime de elegibilidade. É por meio de diretrizes, manuais, consultorias do ACNUR que muitas práticas são levadas para os sistemas nacionais de refúgio. Como dito anteriormente, em muitos país em que há chegada massiva de refugiados, não há análise individual dos pedidos nos moldes do processo de elegibilidade. De acordo com o consultor, "o Brasil não precisa fazer reconhecimento prima facie com a quantidade de solicitantes que tem". Não precisar é diferente de não poder. De todo modo, o fato do Brasil não receber tantos refugiados se comparado às proporções mundiais poderia levar à interpretação de que é possível no caso nacional fazer uma análise mais flexível dos pedidos, porém o argumento foi utilizado para reforçar a importância de aprimorar a avaliação de credibilidade individual das solicitações.

\footnotetext{
${ }^{12}$ Esta prática de contratação de consultoria para avaliar a qualidade e a eficiência dos processos de elegibilidade através do regime de Quality Initiative (QI) que tem como produto um conjunto de recomendações é comum em outros países em que o ACNUR atua.

${ }^{13}$ Os dados do Immigration and Refugee Board of Canada tem sido uma das fontes utilizadas nos pareceres do CONARE para fundamentar as informações dos países de origens.
} 
Em dezembro de 2014, o ACNUR forneceu uma oficina sobre "procedimentos para determinação da condição de refugiado" ${ }^{14}$ aos agentes do Ministério da Justiça (MJ), da sociedade civil e do próprio ACNUR que trabalham com o tema. Além desses, não participaram do treinamento os demais membros do CONARE, muito embora eles todos participem do momento decisório sobre cada pedido de refúgio. No percurso decisório dos pedidos de refúgio, há uma diferenciação na prática entre um primeiro momento, em que ocorrem os procedimentos e as discussões tidos como técnicos, e em um segundo momento, em que ocorre, na Plenária, a decisão efetivamente. Funcionários e representantes dessas três instituições (MJ, sociedade civil e ACNUR) são os que marcam o terreno das disputas sobre o processo e direito de refúgio na fase anterior à Plenária e são eles que geralmente participam das atividades de capacitação.

Nesse sentido, o GEP seria uma fase intermédia, uma vez que dele participam essas três entidades e, nas reuniões que acompanhei e das que tive conhecimento, participam representantes da PF, da DPU e do MRE. A PF apresenta uma peculiaridade porque é o principal órgão estatal de burocracia para os refugiados, mas não estava presente na oficina sobre os procedimentos de determinação de status. É possível justificar essa ausência em decorrência da não obrigatoriedade legal da oitiva pela PF, embora no Rio de Janeiro seja realizada como pré-requisito. Além disso, sua atuação no sistema de refúgio esbarra em algumas desarticulações entre as unidades e entre a representação no CONARE e os agentes que operam os procedimentos. De todo modo, como diz o consultor do ACNUR, "a Polícia Federal é ponto chave para acessibilidade ao processo de solicitação de refúgio". A despeito disso, a PF não é muito ativa nas disputas das denominadas "questões técnicas", que são a grosso modo as discussões sobre formação de critérios para determinação de status e sobre devido processo legal.

Ainda que as decisões na Plenária sobre os casos e sobre políticas para refugiados geralmente não ocorram por voto, a forma de participação de cada membro influencia determinantemente no processo. A indução de posicionamento a partir de algumas falas e

\footnotetext{
${ }^{14}$ A oficina é organizada conjuntamente com a coordenação geral do CONARE, mas norteada pelas diretrizes do ACNUR e pelo que o ACNUR considerada "boas práticas" de parâmetros internacionais para determinação da condição de refugiado.
} 
mesmo as omissões nas discussões afetam o perfil decisório do colegiado. Portanto, a responsabilidade pela decisão é compartilhada por todos os membros. A Plenária é a instância decisória formal, mas as discussões que a antecedem não são de caráter meramente técnico. A definição dos termos e a delimitação das problemáticas ocorrem quase que invariavelmente na primeira fase. Até mesmo o documento encaminhado para aprovação da Plenária é discutido entre alguns membros em momento anterior. As decisões, logo, também são construídas em lugares e momentos diversos.

Não apenas as decisões em si são construídas em processo e nas relações, bem como o é o direcionamento das decisões. As práticas do governo têm dado enfoque à análise de credibilidade cuja motivação anunciada foi tornar o processo mais ágil e mais justo. Neste cenário, nuances se apresentam. O modelo de parecer consolidado cumpre com mais rigor alguns princípios de devido processo legal, sobretudo por apresentar a fundamentação da decisão, prática que não era exercida até então. Todavia, a mudança no formato do parecer não garantiu ao solicitante direito de saber a fundamentação da análise. No Rio de Janeiro, os solicitantes que tiveram seu pedido indeferido, até o momento da pesquisa, têm sido notificados sobre a decisão sem a devida fundamentação. Eles têm acesso às razões do indeferimento tão somente por intermédio da CARJ, que acompanha a tramitação dos pedidos por ser membro do CONARE.

Assim, as práticas em torno do processo de elegibilidade são exercidas com lapsos de transparência quanto à relação com o próprio refugiado. Esse tema de devido processo estava presente na oficina sobre procedimentos para determinação de status. De todo modo, a consultoria contratada enfatizou o enrijecimento do regime de análise de credibilidade cujo um dos seus principais dispositivos se remete à questão da prova nos processos de elegibilidade.

\section{CONCLUSÃO}

O processo de elegibilidade do status de refugiado é pouco considerado no debate geral sobre refúgio. Atribuir a qualidade (jurídica, política e humanitária) de refugiado a um sujeito pode ser compreendido como um procedimento banal ou meramente burocrático. Contudo, a definição legal está associada a disputas pelo sentido de ser refugiado que 
atravessam qualquer paradigma simplista de adequação. Conforme indicam os elementos apresentados ao longo do texto, a categoria de refugiado é construída através de processos administrativos e político-jurídicos.

Em meio a esses processos, a análise de credibilidade é inserida a partir de uma perspectiva de avaliação individual dos pedidos de refúgio. Com isso, os movimentos de fuga são tornados uma questão pessoal e deslocados da coletividade de sua constituição. Trata-se, assim, de uma prática individualizante e totalizante. O medo e o sofrimento, constitutivos do refúgio, são decorrentes de construções e efeitos de poder coletivos, de modo que a avaliação individual incorre no risco de subestimar a complexidade da constituição dos sujeitos. O regime de elegibilidade implica uma razão de governo sobre as vidas como se os indivíduos fossem indivisíveis subjetivamente e naturalmente fixos. A construção do requisito de coerência da análise de credibilidade produz uma negação de emaranhado (ainda que incoerente) de experiências, receios, desejos, temores que têm o potencial de constituírem os ímpetos e as estratégias de luta das pessoas.

Como efeito dos processos de classificação, são tornadas desiguais as narrativas sobre a vida e a legitimidade dos movimentos. A seleção dos refugiados produz técnicas de gestão da heterogeneidade dos êxodos. Deste modo, compreender os processos de construção da condição de refugiado ajuda a entender o funcionamento do Estado e a governamentalidade das práticas dos agentes do universo institucional brasileiro de refúgio.

\section{REFERÊNCIAS}

ACNUR. Perguntas e Respostas. s.d. Disponível em: <http://www.acnur.org/t3/portugues/informacao-geral/perguntas-e-respostas/>. Acesso em: 05 abr. 2015.

2013.

Metodologia e técnicas para entrevistar solicitantes de refúgio. Brasília: DPU,

BRASIL. Lei no 9.474, de 22 de julho de 1997.

BETTS, Alexander; LOESCHER, Gil; MILNER, James. UNHCR: the politics and practice of refugee protection. $2^{\text {a }}$ ed. Oxon: Routledge, 2012. 
BUTLER, Judith; SPIVAK, Gayatri Chakravorty. Who Sings the Nation-State? Calcuta: Seagull, 2010.

FACUNDO NAVIA, Angela. Êxodos e refúgios: colombianos refugiados no Sul e Sudeste do Brasil. Tese (Doutorado em Antropologia Social) - Museu Nacional/PPGAS, Universidade Federal do Rio de Janeiro. Rio de Janeiro, 2014.

FASSIN, Didier. La rasion humanitaire: une histoire morale du temps présent. Paris: Editions du Seuil, 2010.

FOUCAULT, Michel. Microfísica do Poder. Org. Roberto Machado. Rio de Janeiro: Edições Graal, 1979.

. Nascimento da Biopolítica. São Paulo: Martins Fontes, 2008.

GRIFFITHS, Melanie. 'Vile liars and truth distorters': truth, trust and the asylum system. Anthropology Today, v. 28, n. 5, out. 2012.

HADDAD, Emma. The refugee in international society: between sovereigns. New York: Cambridge University Press, 2008.

HERZFELD, Michael. The social production of indifference: exploring the symbolic roots of western bureaucracy. Chicago: The University of Chicago Press, 1992.

REVEL, Judith. Dictionnaire Foucault. Paris: Ellipses, 2008.

VIANNA, Adriana; FACUNDO, Ángela. Tempos e deslocamentos na busca por justiça entre "moradores de favelas" e "refugiados". Ciencia Cultural, São Paulo, v. 67, n. 2, jun. 2015. 